\title{
Are you now a good surgeon? T2 positive margin status as a quality outcome measure following radical prostatectomy
}

\author{
Arees Damani $^{1}$ - Mieke Van Hemelrijck ${ }^{1}$ - Wahyu Wulaningsih ${ }^{1} \cdot$ Danielle Crawley $^{1}$. \\ Declan Cahill ${ }^{2}$
}

Received: 30 December 2015 / Accepted: 18 April 2016 / Published online: 25 April 2016

(C) The Author(s) 2016. This article is published with open access at Springerlink.com

\begin{abstract}
Objective To assess potential biases, such as the reporting pathologist, that may affect objectivity of $\mathrm{T} 2$ positive margin rates as a quality outcome measure following radical prostatectomy.

Patients and methods Prospective data on 183 consecutive LRP patients with pT2 disease, operated on by a single surgeon (2003-2009), were studied. Outcomes were grouped as pre-, peri-, and post-operative and included: age, ethnicity, Gleason score, reporting pathologist, percentage of positive cores, operative time, blood loss, nervesparing status, hospital stay and prostate weight. Descriptive analysis and logistic regression analysis were carried out to compare these variables by positive margin status.

Results A total of $30(16.4 \%)$ positive surgical margins (PSMs) were reported. Surgical stage, earlier date of surgery, and lower prostatic weight showed statistically significant associations with PSM status in both univariate and
\end{abstract}

Arees Damani

arees.damani@kcl.ac.uk

Mieke Van Hemelrijck

mieke.vanhemelrijck@kcl.ac.uk

Wahyu Wulaningsih

wahyu.wulaningsih@kcl.ac.uk

Danielle Crawley

danielle.crawley@kcl.ac.uk

Declan Cahill

declan.cahill@kcl.ac.uk

1 Cancer Epidemiology Group, Division of Cancer Studies,

Research Oncology, School of Medicine, Guy's Hospital,

King's College London, 3rd Floor, Bermondsey Wing,

London SE1 9RT, UK

2 The Royal Marsden NHS Foundation Trust, London, UK multivariate analysis. The reporting pathologist was not found to be predictive of PSMs $(P=0.855)$.

Conclusion We showed that the reporting pathologist does not influence T2 positive margin status, in contrast to tumour characteristics and surgeon experience. T2 positive margin assessment therefore appears to be an objective quality outcome measure.

Keywords Radical prostatectomy · Outcomes assessment · Prostate cancer · Positive margins · Laparoscopic surgery

\section{Introduction}

The gold standard measure of surgeon performance for radical prostatectomy would include patient reported outcomes such as continence, quality of life with PSA follow-ups; however, this is rarely practical in the clinical setting. There is therefore a need for a more easily attainable, unbiased marker of surgical performance. We recently showed that $\mathrm{T} 2$ positive margin rate is the most informative quality outcome measure with the least potential observer bias [1]. This highlights the possible use of T2 positive margin rates as a single objective outcome measure indicative of surgeon skill. Positive surgical margins (PSMs) have been studied in depth to analyse their clinical implications following radical prostatectomy (RP). Stephenson et al. conducted a study looking at 11,521 patients who underwent a RP between 1987 and 2005 and found no association between margin status and cancer-specific mortality within 15 years post-RP. However, they did observe a positive association with biochemical recurrence, so that it is recommended to avoid PSMs where possible [2]. 
Intra-prostatic incision (IPI) is associated with significantly increased biochemical recurrence (BCR), compared to patients with negative surgical margins with or without extra-prostatic extension. The 5-year biochemical recurrence-free survival was only $77 \%$ for patients with intraprostatic incision, compared to $94 \%$ for those without ( $P \leq 0.0001)$, according to Preston et al. [3]. Similar results have also been shown in other studies $[4,5]$. There is thus a growing body of evidence to support PSMs as a prognostic factor indicative of biochemical recurrence following RP.

In addition to its value as a diagnostic predictor, PSM have been suggested to be a good indicator of surgeons' performance. Vickers et al. [6] showed that surgeons who performed higher volumes of RP showed a decrease in PSMs over time, with a plateau after 250 procedures-suggesting that PSM rates can be used to monitor surgeons' experience. Although this data were published for the open procedure, laparoscopic procedures have a similar learning curve as shown by Secin et al. [7] who showed a similar learning curve plateauing after 200-250 cases. Whilst pathological factors have been shown to influence margin status, surgeon skill and experience also may play an important role. Eastham et al. [8] showed that high-volume surgeons had significantly lower PSM rates. It has been suggested that intraprostatic incision may be a better quality measure of surgeon experience than PSM rates [9]. However, rates of intra-prostatic incisions vary greatly between studies. This is potentially due to the difficulty in differentiating between true $\mathrm{T} 2$ positive margins and extra-prostatic extension [9-11].

We have therefore evaluated the clinical variables that may affect T2 PSMs to determine whether this can be used as an objective measurement of surgeon skill and experience.

\section{Methodology}

\section{Study population}

We obtained prospective data for 183 consecutive patients who underwent laparoscopic radical prostatectomy (LRP) between 2003 and 2009. A single surgeon carried out all procedures. The surgeon reported all data pre-, peri- and post-operatively. All data were also verified in the electronic medical records. Only patients with T2 stage disease as classified by TNM staging [12] were included in the study.

\section{Margin status}

Information on margin status was collected post-operatively. A PSM was reported when cancer cells were seen touching or extending beyond the inked resection margin, and were all identified in one Pathology Department by 10 different consultant pathologists, using standard procedures. PSM location was described as apical, circumferential or both. The pathologists are all dedicated consultant uropathologists employed in a teaching hospital. Inter-pathologist review of specimens is carried out as part of an internal-audit.

\section{Clinical variables}

Pre-operative, peri-operative, and post-operative variables were studied in relation to margin status.

Pre-operative variables included age at surgery, ethnicity, Gleason Score (primary and secondary), TNM staging, PSA, and percentage positive cores. Age at surgery was categorised into $\leq 60$ and $>60$ as older age is an important clinical determinant of prostate cancer [13]. Total Gleason score was divided into three categories $(\leq 6,7, \geq 8)[14]$, which corresponded to different survival profiles [15]. PSA was divided into categories of $\leq 10$ and $>10 \mathrm{ng} / \mathrm{ml}$. The percentage of positive cores was studied as a categorical variable ( $<25 \%, 25-49 \%, \geq 50 \%)$. Date of surgery was studied as a categorical variable (2003-2004, 2005-2006, $2007-$ 2009), as a measure of increasing surgeon experience.

Peri-operative variables were reported by the surgeon and included operative time, blood loss and neurovascular bundle (NVB) resection status. NVB status was assessed as no NVB, unilateral and bilateral NVB. Operative time (minutes) was measured as the time from the first incision to the last suture. Blood loss $(\mathrm{ml})$ was recorded from the suction system in theatre.

Post-operative variables studied included prostate weight as reported by the pathologists. Length of hospital stay (days) obtained from the medical record.

\section{Statistical analysis}

Statistical analysis was carried out using Statistical Analysis Systems (SAS) release 9.4 (SAS Institute, Cary, NC).

Univariable logistic regression analysis was performed for each clinical variable to assess their associations with margin status. A test for trend was conducted by assigning categories as an ordinal scale. To further assess this association while adjusting for potential confounding factors, multivariable analysis was performed by incorporating all clinical variables in the model. Finally, to assess any differences by margin location only in patients with PSM $(n=30)$, one-way ANOVA and Chi-square tests were performed for each clinical variable with respect to the three margin locations (apical, circumferential or both).

\section{Results}

Descriptive statistics of the patient cohort for pre-operative variables are presented in Table 1 , with peri- and 
post-operative variables in Table $2.53 \%$ of patients were $>60$ years of age at time of surgery. The majority was of a white background and presented with PSA $\leq 10 \mathrm{ng} / \mathrm{ml}$ $(77 \%)$, with a Gleason score of $\leq 6(60 \%)$. NVB resection was performed unilaterally in 29 patients $(16 \%)$ and bilaterally in $68(37 \%)$. Mean hospital stay was 2 days. $49.7 \%$ of procedures were carried out between 2007 and 2009, when the surgeon was more experienced.

Surgical stage showed a statistically significant correlation with PSM status in both univariate $(P=0.035)$ (Table 3) and multivariate analysis $(P=0.004)$ (Table 4). Patients with higher surgical stage of T2b and T2c were more likely to have PSMs (OR 8.7 (95\% CI 1.07-70.71) and OR 4.1 (95\% CI 0.52-33.27), respectively) than those with T2a disease. Earlier date of surgery was statistically significantly associated with higher PSM rates in both univariate (Table 3) and multivariate analysis (Table 4) $(P=0.018)$. PSMs were also most prevalent in patients with prostatic weight between 20 and $59 \mathrm{~g}$. PSMs were not associated with the reporting pathologist $(P=0.855)$.

In contrast with the univariate analysis, larger prostatic weight $(>100 \mathrm{~g})$ showed a higher predictive value for PSM in multivariate analysis (Table 4). Multivariable analysis also showed NVB resection status to be associated with PSMs, with more PSM in patients in whom NVB resection was not attempted $(P=0.037)$.

Table 1 Descriptive statistics for pre-operative variables

\begin{tabular}{lll}
\hline & Frequency/mean & $\% / \mathrm{SD}$ \\
\hline Pre-operative variables & & \\
Age at surgery (years) & & \\
$\leq 60$ & 86 & 47.3 \\
$>60$ & 96 & 52.7 \\
Date of surgery & & \\
2003-2004 & 44 & 24.0 \\
$2005-2006$ & 48 & 26.2 \\
$2007-2009$ & 91 & 49.7 \\
Ethnicity & & \\
Black & 37 & 20.2 \\
White & 134 & 73.2 \\
Other & 3 & 1.6 \\
Missing & 9 & 4.9 \\
PSA (ng/ml) & & \\
$\leq 10$ & 141 & 77.0 \\
$>10$ & 40 & 21.9 \\
Missing & 2 & 1.3 \\
Percentage cores positive $(\%)$ & \\
$<25 \%$ & 55 & 30.1 \\
$25-49 \%$ & 56 & 30.1 \\
$\geq 50 \%$ & 38 & 20.8 \\
Missing & 34 & \\
\hline & & \\
\hline & &
\end{tabular}

Finally, we assessed whether any of the clinical variables studied were differentially distributed across PSM locations (Table 5). Highest mean blood loss was observed in multifocal PSMs (apex and circumferential) $(883.3 \mathrm{ml}$, $P=0.006)$. Patients with apical PSMs mostly had T2c disease, whereas those with circumferential PSMs had the highest proportion of $\mathrm{T} 2 \mathrm{~b}$ disease $(P=0.01)$.

\section{Discussion}

Our multivariate analyses showed that several clinical variables are predictive of T2 PSMs, including nerve-sparing

Table 2 Descriptive statistics for peri, and post-operative variables

\begin{tabular}{|c|c|c|}
\hline \multicolumn{3}{|l|}{ Peri-operative variables } \\
\hline Mean blood loss (ml) & 279 & 225 \\
\hline Mean operative time (min) & 159 & 37 \\
\hline \multicolumn{3}{|l|}{ Nerve-sparing status } \\
\hline None & 38 & 20.8 \\
\hline Unilateral & 29 & 15.8 \\
\hline Bilateral & 68 & 37.2 \\
\hline Missing & 48 & 26.2 \\
\hline \multicolumn{3}{|l|}{ Post-operative variables } \\
\hline Mean hospital stay (days) & 2 & 2.12 \\
\hline \multicolumn{3}{|l|}{ Prostate weight (g) } \\
\hline $20-59$ & 100 & 54.6 \\
\hline $60-99$ & 49 & 26.8 \\
\hline$\geq 100$ & 13 & 7.1 \\
\hline Missing & 21 & 11.5 \\
\hline \multicolumn{3}{|l|}{ Pathologist } \\
\hline 1 & 67 & 36.6 \\
\hline 2 & 7 & 3.8 \\
\hline 3 & 10 & 5.5 \\
\hline 4 & 53 & 29 \\
\hline 5 & 9 & 4.9 \\
\hline 6 & 1 & 0.5 \\
\hline 7 & 11 & 6.0 \\
\hline 8 & 1 & 0.5 \\
\hline 9 & 5 & 2.7 \\
\hline 10 & 4 & 2.2 \\
\hline Missing & 15 & 8.2 \\
\hline \multicolumn{3}{|l|}{ Surgical stage } \\
\hline $\mathrm{T} 2 \mathrm{a}$ & 30 & 16.4 \\
\hline $\mathrm{T} 2 \mathrm{~b}$ & 52 & 28.4 \\
\hline $\mathrm{T} 2 \mathrm{c}$ & 96 & 52.5 \\
\hline $\mathrm{T} 2 \mathrm{x}$ & 5 & 2.7 \\
\hline \multicolumn{3}{|l|}{ Total Gleason } \\
\hline$\leq 6$ & 109 & 59.6 \\
\hline 7 & 60 & 32.8 \\
\hline$\geq 8$ & 13 & 7.1 \\
\hline
\end{tabular}


Table 3 Univariate analysis of pre, peri and post-operative variables

$\begin{array}{llll}\begin{array}{l}\text { Positive surgical margin } \\ (N=30)\end{array} & \begin{array}{l}\text { Negative surgical margins } \\ (N=153)\end{array} & 95 \% \text { Confidence interval ratio } & P_{\text {trend }}\end{array}$

Pre-operative variables

Age at surgery (years)

$\begin{array}{ll}\leq 60 & 19(22 \%) \\ >60 & 11(11 \%) \\ \text { Date of surgery } & \\ 2003-2004 & 13(30 \%) \\ 2005-2006 & 7(15 \%) \\ 2007-2009 & 10(11 \%) \\ \text { Ethnicity } & \end{array}$

$\begin{array}{lll}67(78 \%) & 1 & \text { Ref } \\ 85(89 \%) & 0.46 & 0.20-1.02 \\ 31(70 \%) & 1 & \text { Ref } \\ 41(85 \%) & 0.41 & 0.15-1.14 \\ 81(89 \%) & 0.29 & 0.12-0.74\end{array}$

0.057

Ethnicity

Black
White
Other + missing
PSA (ng/ml) (SD)

$\leq 10$
$>10$

Percentage cores positive (\%)

$\begin{array}{ll}<25 \% & 8(15 \%) \\ 25-49 \% & 10(18 \%) \\ \geq 50 \% & 8(21 \%) \\ \text { Missing } & 4\end{array}$

Peri-operative variables

Mean blood loss (mls) (SD) 299.8 (363.7)

Mean operative time (min) (SD) 160.8 (39.06)

Nerve-sparing status

None
Unilateral
Bilateral
Missing

Post-operative variables

Mean Hospital stay (days) (SD) 2.07 (1.2)

Prostate Weight (g)

$\begin{array}{ll}20-59 & 24(24 \%) \\ 60-99 & 3(5 \%) \\ \geq 100 & 2(15 \%) \\ \text { Missing } & 1\end{array}$

28

113

12

114

37

$47(85 \%)$

$46(82 \%)$

$30(79 \%)$

30

274.8 (185.4)

$158.0(37.1)$

29

25

57

42

$2.02(2.26)$

$76(76 \%)$

$46(95 \%)$

$11(85 \%)$

20

\section{1}

0.58

$\mathrm{n} / \mathrm{a}$

$\mathrm{n} / \mathrm{a}$

1

0.34

0.093

Ref

0.10-1.19

0.720

Ref

0.46-3.52

$0.53-4.62$

$0.22-2.83$

0.78

1.00

1.00

0.99-1.00

0.99-1.01

0.580

0.708

0.219

Ref

0.52

0.14-1.88

$0.23-1.67$

0.62

$0.23-3.47$

0.46

1.01

$0.84-1.21$

0.911

0.035

Ref

0.06-0.72

$0.12-2.78$

$0.02-1.24$

0.16

0.855

Pathologist

\begin{tabular}{ll}
1 & 10 \\
2 & 4 \\
3 & 1 \\
4 & 11 \\
5 & 0 \\
6 & 0 \\
7 & 3 \\
8 & 0 \\
9 & 1 \\
10 & 0 \\
\hline
\end{tabular}

57
3
9
42
9
1
8
1
4
4

1

7.60

0.63

1.49

$\mathrm{n} / \mathrm{a}$

n/a

2.14

n/a

1.43

n/a
Ref

1.47-39.21

$0.07-5.56$

0.58-3.84

$\mathrm{n} / \mathrm{a}$

$\mathrm{n} / \mathrm{a}$

0.48-9.46

$\mathrm{n} / \mathrm{a}$

0.14-14.10

$\mathrm{n} / \mathrm{a}$ 
Table 3 continued

\begin{tabular}{|c|c|c|c|c|c|}
\hline & $\begin{array}{l}\text { Positive surgical margin } \\
(N=30)\end{array}$ & $\begin{array}{l}\text { Negative surgical margins } \\
(N=153)\end{array}$ & Odds ratio & $95 \%$ Confidence interval & $P_{\text {trend }}$ \\
\hline Surgical stage (\%) & & & & & 0.035 \\
\hline $\mathrm{T} 2 \mathrm{a}$ & 1 & 29 & 1 & Ref & \\
\hline $\mathrm{T} 2 \mathrm{~b}$ & 12 & 40 & 8.70 & $1.07-70.71$ & \\
\hline $\mathrm{T} 2 \mathrm{c}$ & 12 & 84 & 4.14 & $0.52-33.27$ & \\
\hline $\mathrm{T} 2 \mathrm{x}$ & 5 & 0 & $\mathrm{n} / \mathrm{a}$ & $\mathrm{n} / \mathrm{a}$ & \\
\hline Total Gleason & & & & & 0.187 \\
\hline$\leq 6$ & 22 & 87 & 1 & Ref & \\
\hline 7 & 6 & 54 & 0.44 & $0.17-1.15$ & \\
\hline$\geq 8$ & 2 & 11 & 0.72 & $0.15-3.48$ & \\
\hline
\end{tabular}

status and tumour characteristics. Fewer PSM were seen with later date of surgery, confirming the notion of a surgical learning curve in RP procedures. The reporting pathologist and Gleason score were not associated with $\mathrm{T} 2$ positive margin status.

PSMs have been extensively studied to determine their clinical significance. Several studies have outlined the prognostic value of PSMs [2, 10, 16-20]. It is clear that while PSMs are not strongly linked to cancer-specific survival, PSMs are an important predictor of BCR. For these reasons, PSM rates are increasingly being reported as a quality measure, indicating superior surgeon experience and skill. However, few studies to date have investigated factors that may influence margin status apart from surgical experience and tumour characteristics. Although we limited our analysis to patients with pT2 stage, we assessed several clinical variables predictive of prostate cancer prognosis including, pre-operative PSA and Gleason score.

Surgeon experience has a large impact on PSM rate. Vickers et al. [21] showed that PSM rates were significantly improved when treated by a surgeon who had completed at least 250 procedures compared to a surgeon who had completed only 10 . Our study has also shown this to be the case. Patients who underwent a RP between 2007 and 2009 had a lower PSM rate, compared to those in 2005-2006 (OR 0.312 vs OR 0.417). This was also true of patients undergoing surgery in 2005-2006 compared to those in 2003-2004 (OR 0.417 vs OR 1). The British Association of Urological Surgeons (BAUS) recently published surgeon reported data regarding transfusion, length of stay and complication rates across the UK but positive margin rates were not published [22]. The current study includes margin data and shows a clear link between surgeon experience and positive margin rates $\mathrm{T} 2$ disease. The surgeon in our study has had extensive training for the laparoscopic procedure. He undertook some assisting as a trainee and did part procedure cases as a primary surgeon. In addition he underwent 7 months of fellowship training in Institute Montsouris, Paris, which involved assisting, and gaining dry and wet laboratory training.

Our study only included T2 disease and therefore looked at the impact of surgical stage on PSMs on a finer basis. We showed a significant association between T2 PSMs and surgical stage between subclasses in T2 disease (T2 a, b and c). Increasing tumour volume makes incision of the prostate more likely in $\mathrm{T} 2$ disease.

Lower prostatic weight has also been shown to be an independent predictor of IPI due to the surgical difficulty involved in removing a small gland. [9, 23-25]. Marchetti et al. (2011) [25] found that predicted probability of a PSM was $22 \%$ for patients with $<25$ g prostates, which decreased to just $1 \%$ for those with $>150 \mathrm{~g}$ prostates. Our study also showed lower prostatic weight (20-59 g) to be a predictor of T2 PSMs in the univariate analysis. In multivariate analysis, prostates $>100 \mathrm{~g}$ had highest PSM rates. Patients with large prostates constituted a small number of more difficult cases and hence resulted in higher positive margin rates. Higher blood loss was associated with multifocal PSMs $(P=0.006)$. Higher blood loss is a surrogate for surgical difficulty and hence makes surgical incision of the prostate more likely.

PSMs have also been associated with nerve-sparing status. Due to the close approximation of the NVBs to the posterolateral prostate gland, this is the most common site for iatrogenic IPI [4, 5, 9, 10, 26]. Here, NVB status was not associated with margin location in the multivariable analysis, contradicting the literature [27]. Patients who did not undergo NVB sparing procedures had higher incidence of PSMs than those with nerve-sparing procedures. Nonnerve-sparing surgery was more likely in high-volume T2 disease. High-volume disease in the non-nerve spare group makes prostatic incision more likely (apex and base) and can explain why higher PSM rates were seen in this group 
Table 4 Multivariate analysis of pre, peri, and post-operative variables

\begin{tabular}{|c|c|c|c|}
\hline & \multicolumn{3}{|c|}{ Multivariable } \\
\hline & OR & $95 \% \mathrm{CI}$ & $P_{\text {trend }}$ \\
\hline \multicolumn{4}{|l|}{ Pre-operative variables } \\
\hline Age at surgery (years) & & & 0.042 \\
\hline$\leq 60$ & 1 & Ref & \\
\hline$>60$ & 0.24 & $0.06-0.95$ & \\
\hline Date of surgery & & & 0.018 \\
\hline 2003-2004 & 1 & Ref & \\
\hline 2005-2006 & 0.44 & $0.04-5.22$ & \\
\hline 2007-2009 & 0.31 & $0.03-3.62$ & \\
\hline Ethnicity & & & 0.070 \\
\hline Black & 1 & Ref & \\
\hline White & 0.71 & $0.19-2.70$ & \\
\hline Other + missing & $\mathrm{n} / \mathrm{a}$ & $\mathrm{n} / \mathrm{a}$ & $\mathrm{n} / \mathrm{a}$ \\
\hline PSA (ng/ml) & & & 0.131 \\
\hline$\leq 10$ & 1 & Ref & \\
\hline$>10$ & 0.29 & $0.06-1.45$ & \\
\hline Percentage cores positive $(\%)$ & & & 0.898 \\
\hline$<25 \%$ & 1 & Ref & \\
\hline $25-49 \%$ & 1.57 & $0.32-7.62$ & \\
\hline$\geq 50 \%$ & 1.83 & $0.38-8.84$ & \\
\hline Missing & 0.97 & $0.13-7.19$ & \\
\hline \multicolumn{4}{|l|}{ Peri-operative variables } \\
\hline Blood loss (mls) & 1.00 & $0.99-1.00$ & 0.576 \\
\hline Op time (min) & 0.99 & $0.97-1.01$ & 0.458 \\
\hline Nerve-sparing status & & & 0.037 \\
\hline None & 1 & Ref & \\
\hline Unilateral & 0.24 & $0.03-1.72$ & \\
\hline Bilateral & 0.19 & $0.04-1.00$ & \\
\hline Missing & 0.17 & $0.03-1.01$ & \\
\hline \multicolumn{4}{|l|}{ Post-operative variables } \\
\hline Surgical stage & & & 0.004 \\
\hline $\mathrm{T} 2 \mathrm{a}$ & 1 & Ref & \\
\hline $\mathrm{T} 2 \mathrm{~b}$ & 6.52 & $0.63-67.01$ & \\
\hline $\mathrm{T} 2 \mathrm{c}$ & 7.52 & $0.50-113.26$ & \\
\hline $\mathrm{T} 2 \mathrm{x}$ & $\mathrm{n} / \mathrm{a}$ & $\mathrm{n} / \mathrm{a}$ & \\
\hline Prostate weight (g) & & & 0.031 \\
\hline $20-59$ & 1 & Ref & \\
\hline $60-99$ & 0.35 & $0.08-1.52$ & \\
\hline$\geq 100$ & 1.29 & $0.13-12.96$ & \\
\hline Missing & 0.16 & $0.02-1.64$ & \\
\hline Total Gleason & & & 0.148 \\
\hline$\leq 6$ & 1 & Ref & \\
\hline 7 & 0.18 & $0.04-0.90$ & \\
\hline$\geq 8$ & 0.63 & $0.08-4.84$ & \\
\hline Mean hospital stay (days) & 0.88 & $0.63-1.21$ & 0.427 \\
\hline
\end{tabular}

of patients. A limit to our study was that information on the grade of nerve spare (partial, inter-fascial, intra-fascial) was not available as this may have an impact on the risk of PSMs.

IPI refers to iatrogenic incision into the prostate that contains cancer. There is great variability in the rates of IPI reported by different studies. For example, several studies have found incidence of IPI to be $1.8-2.8 \%[9,11,28]$. However, some studies have reported rates of IPI as high as $20 \%$ [29]. Indeed, in our study, 30 patients (16.4\%) presented with PSMs in T2 disease (IPI). One possible explanation is difficulty in pathologic interpretation of surgical margin status, as has been highlighted by a number of studies [9-11]. There is a recognised danger for over-calling PSMs because of difficulty in differentiating between extraprostatic extension (EPE) and IPI [10]. Despite recently published guidelines on standardised handling of RP specimens by the International Society of Urological Pathology (ISUP) (2009), there is still a lack of consistency in the reporting of surgical margins [30].

A study by van der Kwast et al. [31]. highlights the inter-observer variation in the reporting of positive margin status. External review of pathology reports was carried out for patients in the European Organisation for Research and Treatment of Cancer trial (EORTC). There was only a $57.5 \%$ agreement for extra-prostatic extension, and $69.4 \%$ concordance for surgical margin status. A total of $24.9 \%$ of the cases that were called positive at the local hospital were subsequently called negative on review in the study. More recent evidence has contradicted these findings, showing agreement in over $87 \%$ of cases regarding margin status [32].

This evidence supports the fact that pathologists may interpret PSMs differently and calls into question the objectivity of surgical margin status as a quality measure. However, in our study, we found no such correlation between the reporting pathologist and margin status in both univariate and multivariate analysis. Therefore, it seems unlikely that the reporting pathologist has an impact on T2 PSM rates reported by different surgeons. It is more likely that any differences between T2 PSM rates reported by different surgeons are down to surgical experience, and tumour characteristics, not external bias.

One of the particular strengths of this study was the use of data from a single surgeon. This removes the heterogeneity of surgeon skills and allows valid comparisons of PSM rate over time. Only 30 PSMs were present in our study and therefore reduced the statistical power of our analysis. However, our PSM rate was comparable with 
Table 5 Analysis of variables by positive margin location

\begin{tabular}{|c|c|c|c|c|}
\hline & $\operatorname{Apex}(\%) N=15$ & Circumferential (\%) $N=12$ & Apex and circumferential $(\%) N=3$ & $P$ value \\
\hline Age at time of surgery (years) & & & & 0.898 \\
\hline$\leq 60$ & $10(62.5)$ & $7(58.3)$ & $2(66.7)$ & \\
\hline$>60$ & $5(31.3)$ & $5(41.7)$ & $1(33.3)$ & \\
\hline Missing & $1(6.3)$ & $0(0.0)$ & $0(0.0)$ & \\
\hline Ethnicity & & & & 0.924 \\
\hline Black & $4(26.7)$ & $4(33.3)$ & $1(33.3)$ & \\
\hline White & $11(73.3)$ & $8(66.7)$ & $2(66.7)$ & \\
\hline Other & $0(0)$ & $0(0)$ & $0(0)$ & \\
\hline Mean PSA (ng/ml) & & & & 0.189 \\
\hline$\leq 10$ & $12(80.0)$ & $12(100)$ & $3(100)$ & \\
\hline$>10$ & $3(20.0)$ & $0(0)$ & $0(0)$ & \\
\hline Mean percentage cores positive (\%) & & & & 0.057 \\
\hline$<25 \%$ & $0(0)$ & $7(58.3)$ & $1(33.3)$ & \\
\hline $25-49 \%$ & $7(46.7)$ & $2(16.7)$ & $1(33.3)$ & \\
\hline$>50 \%$ & $5(33.3)$ & $2(16.7)$ & $1(33.3)$ & \\
\hline Missing & $3(20.0)$ & $1(8.3)$ & $0(0)$ & \\
\hline Mean blood loss (mls) (SD) & $182.33(87.7)$ & $300.83(237.2)$ & $883.33(970.0)$ & 0.006 \\
\hline Mean operative time (min) (SD) & $153(34.4)$ & $170.83(45.9)$ & $160(34.6)$ & 0.515 \\
\hline Mean hospital stay (days) (SD) & $2.27(1.3)$ & $1.67(0.7)$ & $2.67(2.1)$ & 0.297 \\
\hline Mean prostate weight $(\mathrm{g})$ & & & & 0.442 \\
\hline $20-59$ & $12(80.0)$ & $10(83.3)$ & $2(66.7)$ & \\
\hline $60-99$ & $2(13.3)$ & $1(8.3)$ & $0(0.0)$ & \\
\hline$\geq 100$ & $0(0.0)$ & $1(8.3)$ & $1(33.3)$ & \\
\hline Missing & $1(6.7)$ & $0(0.0)$ & $0(0.0)$ & \\
\hline Pathologist & & & & 0.144 \\
\hline 1 & $7(30.4)$ & $3(15.8)$ & $0(0.0)$ & \\
\hline 2 & $1(4.3)$ & $2(10.5)$ & $1(33.3)$ & \\
\hline 3 & $0(0.0)$ & $1(5.3)$ & $0(0.0)$ & \\
\hline 4 & $5(21.7)$ & $5(26.3)$ & $1(33.3)$ & \\
\hline 5 & $0(0.0)$ & $0(0.0)$ & $0(0.0)$ & \\
\hline 6 & $0(0.0)$ & $0(0.0)$ & $0(0.0)$ & \\
\hline 7 & $2(8.7)$ & $1(5.3)$ & $0(0.0)$ & \\
\hline 8 & $0(0.0)$ & $0(0.0)$ & $0(0.0)$ & \\
\hline 9 & $0(0.0)$ & $0(0.0)$ & $1(33.3)$ & \\
\hline 10 & $0(0.0)$ & $0(0.0)$ & $0(0.0)$ & \\
\hline Missing $=15$ & $8(34.8)$ & $7(36.8)$ & $0(0.0)$ & \\
\hline Nerve-sparing status & & & & 0.535 \\
\hline None & $3(20.0)$ & $5(41.7)$ & $1(33.3)$ & \\
\hline Unilateral & $2(13.3)$ & $1(8.3)$ & $1(33.3)$ & \\
\hline Bilateral & $5(33.3)$ & $5(41.7)$ & $1(33.3)$ & \\
\hline Missing & $5(33.3)$ & $1(8.3)$ & $0(0.0)$ & \\
\hline Surgical stage & & & & 0.010 \\
\hline $\mathrm{T} 2 \mathrm{a}$ & $0(0.0)$ & $0(0.0)$ & $1(33.3)$ & \\
\hline $\mathrm{T} 2 \mathrm{~b}$ & $4(26.7)$ & $8(66.7)$ & $0(0.0)$ & \\
\hline $\mathrm{T} 2 \mathrm{c}$ & $9(60.0)$ & $2(16.7)$ & $1(33.3)$ & \\
\hline $\mathrm{T} 2 \mathrm{x}$ & $2(13.3)$ & $2(16.7)$ & $1(33.3)$ & \\
\hline Total Gleason & & & & 0.626 \\
\hline "6 & $10(62.5)$ & $10(83.3)$ & $2(66.7)$ & \\
\hline
\end{tabular}


Table 5 continued

\begin{tabular}{lccc}
\hline & Apex $(\%) N=15$ & Circumferential $(\%) N=12$ & Apex and circumferential $(\%) N=3 \quad P$ value \\
\hline 7 & $3(18.8)$ & $2(16.7)$ & $1(33.3)$ \\
$\geq 8$ & $2(12.5)$ & $0(0.0)$ & $0(0.0)$ \\
Missing & $1(6.3)$ & $0(0.0)$ & $0(0.0)$ \\
Date of surgery & & & $1(33.3)$ \\
$2003-2004$ & $5(33.3)$ & $7(58.3)$ & $1(33.3)$ \\
$2005-2006$ & $4(26.7)$ & $2(16.7)$ & $1(33.3)$ \\
$2007-2009$ & $6(40.0)$ & $3(25.0)$ & 0.751 \\
\hline
\end{tabular}

other studies of a similar nature, for example Kumano et al. (2009) [29], suggesting that the population was representative. Another limitation of the current study was that data were missing for many of the patients in our database. This was particularly the case for nerve-sparing status. In our study, 48 patients $(26.2 \%)$ were missing data on nervesparing status. Of these 6 had a PSM at surgery, which represents $20 \%$ of the PSMs in our population. This may be one reason why our study contradicted the majority of the literature with regard to the association of NVB resection and PSMs. Time to surgery was not evaluated in our cohort and would be interesting to study in the future, as waiting time may lead to tumour growth and therefore higher risk of PSM than is predicted by the clinical variables.

\section{Conclusion}

In the absence of good patient reported outcomes, T2 positive margin rates are increasingly being used a quality outcome measure of surgeon experience. Our study has shown that T2 positive margin rates are not influenced by external biases such as the reporting pathologist but are affected by tumour characteristics and surgeon skill alone and can therefore be considered as an objective measure of surgeon skill.

Author contributions Arees Damani was involved in data Collection, data analysis, and manuscript writing; Mieke Van Hemelrijck was involved in project development, data analysis, and manuscript editing; Wulaningsih Wahyu was involved in data analysis, and manuscript editing; Danielle Crawley was involved in data analysis, manuscript editing; and Declan Cahill was involved in project development, data collection, and manuscript editing.

\section{Compliance with ethical standards}

Ethical standards There are no ethical considerations to consider in this study.

Conflict of interest There are no conflicts of interest to be stated for the corresponding author and all co-authors.
Open Access This article is distributed under the terms of the Creative Commons Attribution 4.0 International License (http://creativecommons.org/licenses/by/4.0/), which permits unrestricted use, distribution, and reproduction in any medium, provided you give appropriate credit to the original author(s) and the source, provide a link to the Creative Commons license, and indicate if changes were made.

\section{References}

1. Mason S, Van Hemelrijck M, Brown C, Cahill D (2015) Radical prostatectomy outcome data: which parameters are representative and reliable to publish? BAUS 2015 eposter online library. http://baus.multilearning.com/baus/2015/eposter/98876/ undefined

2. Stephenson AJ, Eggener SE, Hernandez AV, Klein EA, Kattan MW, Wood DP Jr et al (2014) Do margins matter? The influence of positive surgical margins on prostate cancer-specific mortality. Eur Urol 65(4):675-680

3. Preston MA, Carriere M, Raju G, Morash C, Doucette S, Gerridzen RG et al (2011) The prognostic significance of capsular incision into tumor during radical prostatectomy. Eur Urol 59(4):613-618

4. Chuang AY, Nielsen ME, Hernandez DJ, Walsh PC, Epstein JI (2007) The significance of positive surgical margin in areas of capsular incision in otherwise organ confined disease at radical prostatectomy. J Urol 178(4 Pt 1):1306-1310

5. Shuford MD, Cookson MS, Chang SS, Shintani AK, Tsiatis A, Smith JA Jr et al (2004) Adverse prognostic significance of capsular incision with radical retropubic prostatectomy. J Urol 172(1):119-123

6. Vickers A, Bianco F, Cronin A, Eastham J, Klein E, Kattan M et al (2010) The learning curve for surgical margins after open radical prostatectomy: implications for margin status as an oncological end point. J Urol 183(4):1360-1365

7. Secin FP, Savage C, Abbou C, de La Taille A, Salomon L, Rassweiler J et al (2010) The learning curve for laparoscopic radical prostatectomy: an international multicenter study. J Urol 184(6):2291-2296

8. Eastham JA, Kattan MW, Riedel E, Begg CB, Wheeler TM, Gerigk $C$ et al (2003) Variations among individual surgeons in the rate of positive surgical margins in radical prostatectomy specimens. J Urol 170(6 Pt 1):2292-2295

9. Park SW, Readal N, Jeong BC, Humphreys EB, Epstein JI, Partin AW et al (2014) Risk factors for intraprostatic incision into malignant glands at radical prostatectomy. Eur Urol 68:311-316

10. Yossepowitch O, Briganti A, Eastham JA, Epstein J, Graefen M, Montironi R et al (2014) Positive surgical margins after radical 
prostatectomy: a systematic review and contemporary update. Eur Urol 65(2):303-313

11. Chuang AY, Epstein JI (2008) Positive surgical margins in areas of capsular incision in otherwise organ-confined disease at radical prostatectomy: histologic features and pitfalls. Am J Surg Pathol 32(8):1201-1206

12. AJCC (2002). What is Cancer Staging? [cited 2015 5/11/15]. https://cancerstaging.org/references-tools/Pages/What-is-Cancer-Staging.aspx

13. Tward JD, Lee CM, Pappas LM, Szabo A, Gaffney DK, Shrieve DC (2006) Survival of men with clinically localized prostate cancer treated with prostatectomy, brachytherapy, or no definitive treatment. Cancer 107(10):2392-2400

14. Emerson RE, Koch MO, Daggy JK, Cheng L (2005) Closest distance between tumor and resection margin in radical prostatectomy specimens: lack of prognostic significance. Am J Surg Pathol 29(2):225-229

15. D'Amico AV, Whittington R, Malkowicz SB, Schultz D, Blank K, Broderick GA et al (1998) Biochemical outcome after radical prostatectomy, external beam radiation therapy, or interstitial radiation therapy for clinically localized prostate cancer. JAMA 280(11):969-974

16. Wright JL, Dalkin BL, True LD, Ellis WJ, Stanford JL, Lange $\mathrm{PH}$ et al (2010) Positive surgical margins at radical prostatectomy predict prostate cancer specific mortality. J Urol 183(6):2213-2218

17. Chalfin HJ, Dinizo M, Trock BJ, Feng Z, Partin AW, Walsh PC et al (2012) Impact of surgical margin status on prostate-cancerspecific mortality. BJU Int 110(11):1684-1689

18. Retel VP, Bouchardy C, Usel M, Neyroud-Caspar I, Schmidlin F, Wirth G et al (2014) Determinants and effects of positive surgical margins after prostatectomy on prostate cancer mortality: a population-based study. BMC Urol 14:86

19. Ploussard G, Agamy MA, Alenda O, Allory Y, Mouracade P, Vordos D et al (2011) Impact of positive surgical margins on prostate-specific antigen failure after radical prostatectomy in adjuvant treatment-naive patients. BJU Int 107(11):1748-1754

20. Boorjian SA, Karnes RJ, Crispen PL, Carlson RE, Rangel LJ, Bergstralh EJ et al (2010) The impact of positive surgical margins on mortality following radical prostatectomy during the prostate specific antigen era. J Urol 183(3):1003-1009

21. Vickers AJ, Bianco FJ, Serio AM, Eastham JA, Schrag D, Klein EA et al (2007) The surgical learning curve for prostate cancer control after radical prostatectomy. J Natl Cancer Inst 99(15):1171-1177
22. BAUS (2015) Radical prostatectomy outcomes data: BAUS; [cited 2015 18/10/2015]. http://www.baus.org.uk/patients/surgical_outcomes/prostatectomy/default.aspx

23. Freedland SJ, Grubb KA, Yiu SK, Nielsen ME, Mangold LA, Isaacs WB et al (2005) Obesity and capsular incision at the time of open retropubic radical prostatectomy. J Urol 174(5):1798-1801

24. Patel VR, Coelho RF, Rocco B, Orvieto M, Sivaraman A, Palmer KJ et al (2011) Positive surgical margins after robotic assisted radical prostatectomy: a multi-institutional study. J Urol 186(2):511-516

25. Marchetti PE, Shikanov S, Razmaria AA, Zagaja GP, Shalhav AL (2011) Impact of prostate weight on probability of positive surgical margins in patients with low-risk prostate cancer after robotic-assisted laparoscopic radical prostatectomy. Urology 77(3):677-681

26. Kwak KW, Lee HM, Choi HY (2010) Impact of capsular incision on biochemical recurrence after radical perineal prostatectomy. Prostate Cancer Prostatic Dis 13(1):28-33

27. Preston MA, Breau RH, Lantz AG, Morash C, Gerridzen RG, Doucette $S$ et al (2015) The association between nerve sparing and a positive surgical margin during radical prostatectomy. Urologic Oncology 33(1):18-e1

28. Barocas DA, Han M, Epstein JI, Chan DY, Trock BJ, Walsh PC et al (2001) Does capsular incision at radical retropubic prostatectomy affect disease-free survival in otherwise organ-confined prostate cancer? Urology 58(5):746-751

29. Kumano M, Miyake H, Muramaki M, Kurahashi T, Takenaka A, Fujisawa M (2009) Adverse prognostic impact of capsular incision at radical prostatectomy for Japanese men with clinically localized prostate cancer. Int Urol Nephrol 41(3):581-586

30. Tan PH, Cheng L, Srigley JR, Griffiths D, Humphrey PA, van der Kwast TH, et al. (2011) International Society of Urological Pathology (ISUP) consensus conference on handling and staging of radical prostatectomy specimens. Working group 5: surgical margins. Mod Pathol. 24(1):48-57

31. van der Kwast T, Collette L, Van Poppel H, Van Cangh P, Vekemans K, DaPozzo L et al (2006) Impact of pathology review of stage and margin status of radical prostatectomy specimens (EORTC trial 22911). Virchows Arch 449(4):428-434

32. Netto GJ, Eisenberger M, Epstein JI (2011) Interobserver variability in histologic evaluation of radical prostatectomy between central and local pathologists: findings of TAX 3501 multinational clinical trial. Urology 77(5):1155-1160 